\title{
Effect of superabsorbent polymers (SAP) on fresh state mortars with ground granulated blast-furnace slag (GGBS)
}

\author{
Fernando do Couto Rosa Almeida, and Agnieszka Joanna Klemm \\ School of Engineering and Built Environment, Glasgow Caledonian University, UK
}

\begin{abstract}
Although cementitious materials are the main construction materials and worldwide produced, there is still a major concern about their sustainability and durability, especially in terms of conserving resources, reducing wastes and decreasing the environmental impacts of repair and replacement. In general, cementitious materials are very susceptible to cracking provoked by autogenous shrinkage due to their associated self-desiccation process. The problem is even more critical in concrete with blended cements, including Portland cement with ground granulated blast-furnace slag (GGBS). The current paper evaluates efficiency of superabsorbent polymers (SAP) as internal curing agents; shrinkage reduction in mortars with different levels of cement replacement by GGBS $(0 \%, 25 \%, 50 \%$ and $75 \%)$ is presented. The study is focused on three types of SAPs with different water absorption/desorption capacities (SAP I: $10 \mathrm{~g} / \mathrm{g}$, SAP II: $25-30 \mathrm{~g} / \mathrm{g}$ and SAP III: $35 \mathrm{~g} / \mathrm{g}$ in cement paste solution). Tests of consistency, density, air content of fresh mortar, setting times and autogenous shrinkage are analysed. The results showed that mortars with SAP can significantly reduce autogenous shrinkage for any studied GGBS content in comparison with the reference mortar. The reduction of autogenous shrinkage by SAP may decrease the cracking susceptibility and hence increase the sustainability level of the material for more durable constructions.
\end{abstract}

\section{INTRODUCTION}

Cementitious material is the most popular and widely used construction material. However, there is still a major concern about their durability and sustainability, especially in terms of improving longterm performance, conserving sources, reducing wastes and decreasing the environmental impacts of repair and replacement.

In order to improve sustainability level of concrete and mortar and to enhance durability and other performance characteristics, supplementary cementitious materials have been developed for the last couple of decades, such as ground granulated blast-furnace slag (GGBS). This by-product of the pig iron manufacture, generated in amounts of the same order of iron, is widely used in blended cements (Oner \& Akyuz 2007).

In general, cementitious materials are very susceptible to cracking provoked by autogenous shrinkage due to their associated self-desiccation process. Even within the first few days of casting, autogenous shrinkage may lead to high restraint stresses and, thus, to crack formation in the mortar or concrete. Unlike drying shrinkage, autogenous shrinkage cannot be reduced significantly by external curing methods. As shown by Hasholt et al.
(2012), Klemm et al. (2012) and Mechtcherine et al. (2013) this problem may be minimized by application of superabsorbent polymers (SAP) into cementitious materials. SAPs can be used as an internal curing agent for cementitious materials due to their high capacity of water absorption and/or release in either fresh or hardened stage. They serve as small water reservoirs evenly distributed across the concrete/mortar volume as they absorb the water from the fresh state (Mechtcherine et al. 2013).

Although the use of SAPs as internal curing agents in cementitious materials has been previously documented in the literature (Jensen \& Hansen 2001; Jensen \& Hansen 2002; Mechtcherine \& Reinhardt 2012; Mechtcherine et al. 2013; Klemm \& Sikora 2013) their suitability for general use, in particular in blended cements with GGBS, is still not clearly articulated and cohesive.

Beushausen et al. (2014) have been investigated the influence of SAPs on strength and durability properties of blended cements mortars, including GGBS. Although mortars with SAP and blended cements may result in a slight retardation of strength development, the authors suggest the long-term strength is possibly not negatively affected by the addition of SAP. 
Snoeck et al. (2015) have been studied the influence of SAP on autogenous shrinkage properties of cement pastes with supplementary cementitious materials, including GGBS. They concluded SAP was able to mitigate autogenous shrinkage in mixture with cement and GGBS. However, the effect of different types of SAPs with different water absorption capacities and kinetics on mortars with GGBS still needs to be evaluated.

Therefore, the proposed paper aimed to evaluate SAP efficiency in shrinkage reduction in fresh state mortars with different levels of cement replacement by GGBS and SAPs with different water absorption capacities.

\section{MATERIALS AND METHODS}

Different mix proportions of mortars were produced for the experimental study, considering different levels of cement replacement by GGBS and different types of SAPs, including reference mortars without GGBS and/or SAP.

CEM I and GGBS has been used as binder materials, considering four levels of Portland cement type I - CEM I 52.5N (BS EN 197-1:2011) replacement by GGBS (BS EN 15167-1:2006): 0\%, $25 \%, 50 \%$ and $75 \%$ by mass. Table 1 shows the chemical and physical analysis as well as Figure 1 shows the SEM micrographs of CEM I and GGBS used in the experimental study.

Table 1. Chemical and physical analysis of CEM I and GGBS.

\begin{tabular}{ccc}
\hline Compound (\%) & CEM I & GGBS \\
\hline $\mathrm{SiO}_{2}$ & 20.07 & 34.53 \\
$\mathrm{Al}_{2} \mathrm{O}_{3}$ & 4.85 & 13.14 \\
$\mathrm{Fe}_{2} \mathrm{O}_{3}$ & 2.72 & 0.21 \\
$\mathrm{CaO}$ & 62.44 & 38.53 \\
$\mathrm{MgO}$ & 2.20 & 9.74 \\
$\mathrm{SO}_{3}$ & 3.15 & 0.35 \\
$\mathrm{Na}_{2} \mathrm{O}$ & 0.31 & 0.17 \\
$\mathrm{~K}_{2} \mathrm{O}$ & 0.62 & 0.59 \\
$\mathrm{Cl}$ & 0.06 & 0.02 \\
$\mathrm{MnO}$ & - & 0.22 \\
$\mathrm{TiO}_{2}$ & - & 0.82 \\
Loss on Ignition & 2.77 & 0.64 \\
\hline Fineness (m $\left.{ }^{2} / \mathbf{k g}\right)$ & 410 & 390 \\
\hline
\end{tabular}
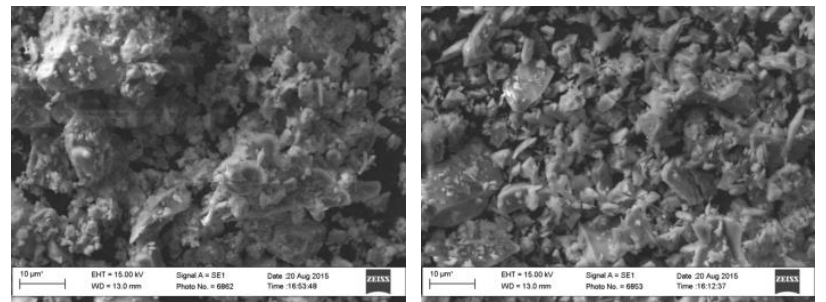

Figure 1. The SEM micrographs of CEM I and GGBS respectively.

Three different types of SAP have been used in the proportion of $0.25 \%$ by mass of binder: SAP I, SAP II and SAP III respectively with water absorption capacity of $10 \mathrm{~g} / \mathrm{g}, 25-30 \mathrm{~g} / \mathrm{g}$ and $35 \mathrm{~g} / \mathrm{g}$ in cement paste solution. Figures 2-4 show the SEM micrographs of used SAPs in dry and wet conditions.
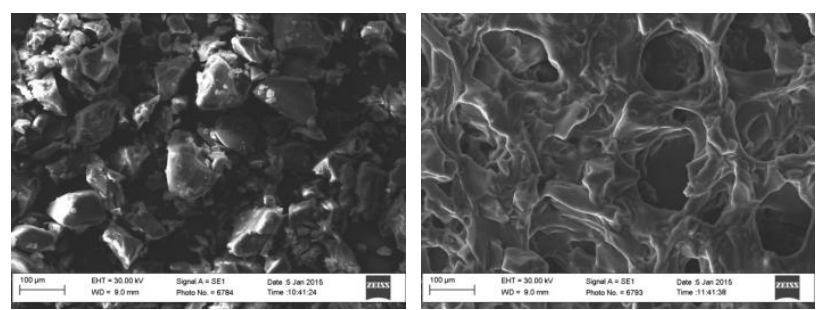

Figure 2. The SEM micrographs of SAP I in dry and wet conditions respectively.
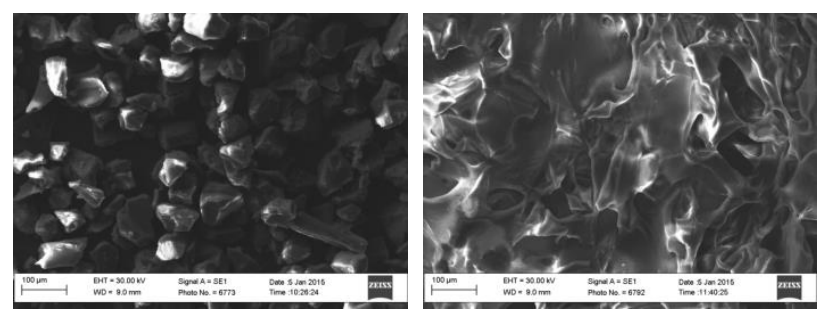

Figure 3. The SEM micrographs of SAP II in dry and wet conditions respectively.
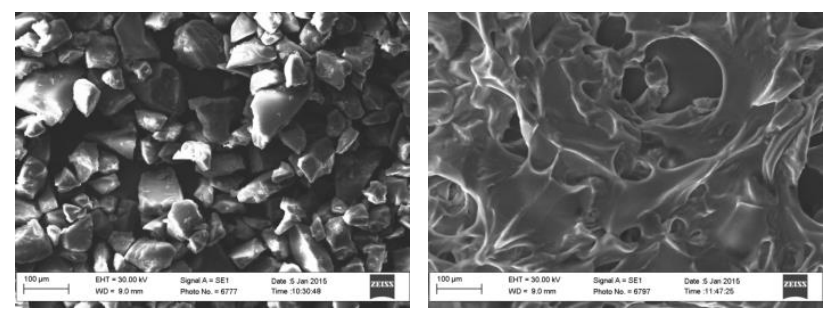

Figure 4. The SEM micrographs of SAP III in dry and wet conditions respectively.

Fine sand used as fine aggregate contained $99.95 \%$ of particles distributed below $0.6 \mathrm{~mm}$. The particle size distribution determined by sieving test (BS EN 13139:2013) is shown in Figure 5. 


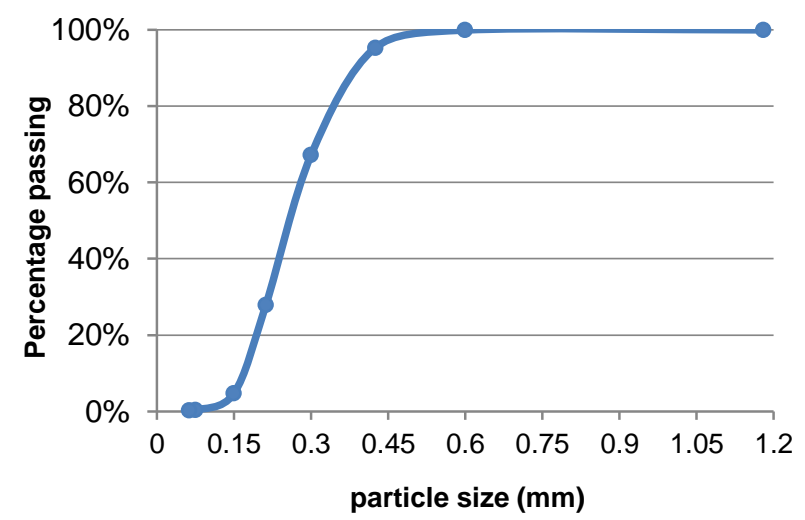

Figure 5. Particle size distribution of sand.

Mortars with mix proportion of 1:2 (binder : sand) and with water-to-binder ratio $(\mathrm{w} / \mathrm{b})$ of 0.5 have been prepared. Table 2 shows the mix proportion (by mass) of all materials used for mortars preparation.

Table 2. Mix proportion of materials used for mortars production (by mass).

\begin{tabular}{ccccccc}
\hline $\begin{array}{c}\text { Sample } \\
\text { name }\end{array}$ & $\begin{array}{c}\text { Type of } \\
\text { SAP }\end{array}$ & CEM I & GGBS & SAP & Sand & Water \\
\hline R0 & - & 1.00 & - & - & 2.00 & 0.50 \\
R25 & - & 0.75 & 0.25 & - & 2.00 & 0.50 \\
R50 & - & 0.50 & 0.50 & - & 2.00 & 0.50 \\
R75 & - & 0.25 & 0.75 & - & 2.00 & 0.50 \\
\hline A0 & I & 1.00 & - & 0.0025 & 2.00 & 0.50 \\
A25 & I & 0.75 & 0.25 & 0.0025 & 2.00 & 0.50 \\
A50 & I & 0.50 & 0.50 & 0.0025 & 2.00 & 0.50 \\
A75 & I & 0.25 & 0.75 & 0.0025 & 2.00 & 0.50 \\
\hline C0 & II & 1.00 & - & 0.0025 & 2.00 & 0.50 \\
C25 & II & 0.75 & 0.25 & 0.0025 & 2.00 & 0.50 \\
C50 & II & 0.50 & 0.50 & 0.0025 & 2.00 & 0.50 \\
C75 & II & 0.25 & 0.75 & 0.0025 & 2.00 & 0.50 \\
\hline D0 & III & 1.00 & - & 0.0025 & 2.00 & 0.50 \\
D25 & III & 0.75 & 0.25 & 0.0025 & 2.00 & 0.50 \\
D50 & III & 0.50 & 0.50 & 0.0025 & 2.00 & 0.50 \\
D75 & III & 0.25 & 0.75 & 0.0025 & 2.00 & 0.50 \\
\hline
\end{tabular}

The following sequence was performed for mixing procedure for all mortars studied:

- 1 minute mixing cement and SAP (if required) at low speed (140 rotation $/ \mathrm{min}$ );

- 1 minute mixing the previous mix adding GGBS (if required) at low speed;

- 2 minutes mixing the previous mix adding sand at low speed;

- 1 minute manually scratching dry materials on the internal wall of the mixer bowl;

- 1 minute adding water with the mixer working at low speed;

- 1 minute mixing the fresh mortar at low speed;
- 1 minute manually scratching adhered mortar on the internal wall and bottom part of the mixer bowl;

- 1 minute of further mixing of the fresh mortar at increased speed (285 rotation/min).

Tests of consistency (flow table method, EN 10153:1999), density (EN 1015-6:1998), air content (pressure method, EN 1015-7:1998) and initial and final setting times (by Vicat apparatus, EN 1963:2005) were carried out for the fresh mortar mixes in laboratory environment (temperature at $21 \pm 2{ }^{\circ} \mathrm{C}$ and relative humidity at $40 \pm 5 \%$ ). Autogenous shrinkage was tested by the corrugated tubes method (Figure 6a) (ASTM C-1698:2009) from the time of final setting until the age of 28 days, using a digital bench dilatometer (Figure 6b).

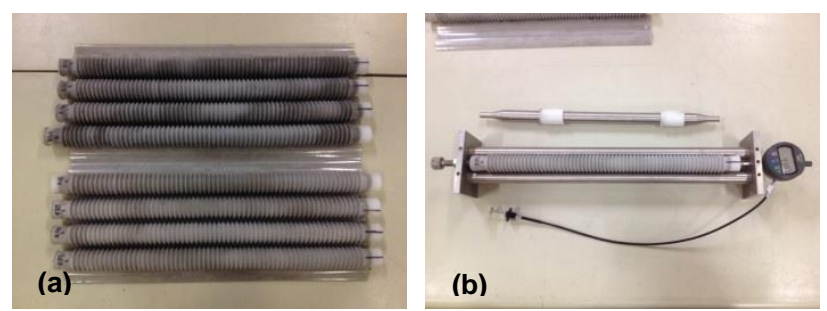

Figure 6. Corrugated tubes (a) and digital bench dilatometer (b) for autogenous shrinkage testing.

The specimens were measured every half hour for the first 8 hours after casting and then at least twice every day.

\section{RESULTS AND DISCUSSION}

Table 3 shows the tests results of fresh state mortars, such as consistency, density and air content.

Table 3. Tests results of fresh state mortars.

\begin{tabular}{cccc}
\hline $\begin{array}{c}\text { Sample } \\
\text { name }\end{array}$ & $\begin{array}{c}\text { Consistency } \\
(\mathbf{m m})\end{array}$ & $\begin{array}{c}\text { Air content } \\
(\mathbf{\%})\end{array}$ & $\begin{array}{c}\text { Density } \\
\left(\mathbf{g} / \mathbf{d m}^{\mathbf{3}}\right)\end{array}$ \\
\hline R0 & 155 & 7.0 & $2,120.5$ \\
R25 & 153 & 6.8 & $2,124.5$ \\
R50 & 151 & 6.6 & $2,127.3$ \\
R75 & 147 & 6.4 & $2,117.3$ \\
\hline A0 & 126 & 7.5 & $2,087.1$ \\
A25 & 125 & 8.4 & $2,081.9$ \\
A50 & 124 & 8.0 & $2,070.0$ \\
A75 & 123 & 7.6 & $2,062.9$ \\
\hline C0 & 132 & 7.4 & $2,082.7$ \\
C25 & 131 & 7.5 & $2,091.2$ \\
C50 & 128 & 7.0 & $2,096.0$ \\
C75 & 124 & 6.8 & $2,070.8$ \\
\hline D0 & 120 & 7.8 & $2,084.3$ \\
D25 & 117 & 8.0 & $2,092.3$ \\
D50 & 113 & 8.5 & $2,068.1$ \\
D75 & 110 & 9.0 & $2,043.2$ \\
\hline
\end{tabular}


The results of flow table test are also shown in Figure 7. Both SAP and GGBS reduced consistency of mortars compared with reference samples.

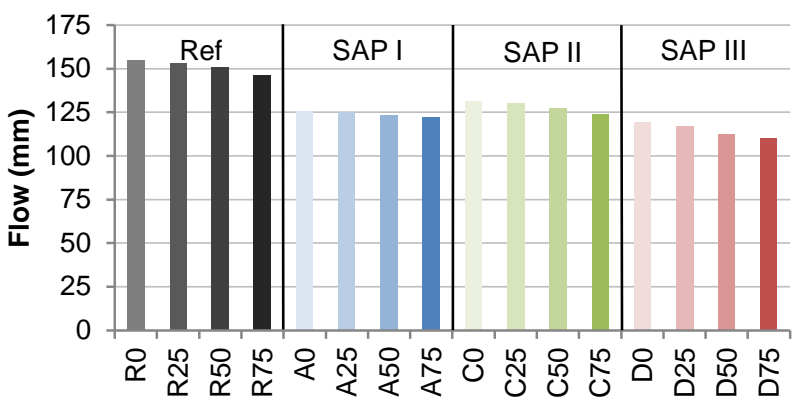

Figure 7. Consistency results by flow table test.

The use of GGBS slightly reduced consistency of the mortars in comparison with samples with lower/no GGBS content. The higher replacement level, the lower is the mortars consistency. The reduction on the workability may be explained by the higher specific surface area of CEM I $\left(410 \mathrm{~m}^{2} / \mathrm{kg}\right)$ compared with that of GGBS $\left(390 \mathrm{~m}^{2} / \mathrm{kg}\right)$ as seen in Table 1. This effect was also verified by Siddique \& Bennacer (2012), where workability of mortar has been increased with the increment in the surface area of GGBS, i.e., finer binder material increased fluidity ratio of mortars. Moreover, due to its slower hydration process, GGBS may be acting as filler in the first minutes of fresh mortars mixes, when the flow property is tested. So, the consistency would be decreased in the presence with higher GGBS contents, as shown by the flow test results.

Besides that, SAP reduced significantly consistency of mortars due to its high water absorption capacity in comparison with samples without SAP. The driest mortars were those samples with SAP III that has the highest absorption capacity between all SAPs studied. However, despite SAP I has the lowest absorption capacity, mortars with SAP II seemed to present better workability than those samples with SAP I. It may indicate that SAP water absorption in fresh state mortars depends not only on their absorption capacity but also their absorption kinetics. Moreover, the type of SAP together with GGBS can affect the consistency of mortars. SAP may minimize the difference in consistence between those mortars with different contents of GGBS. Samples with SAP I were the least sensitive to the level of substitution of GGBS. The water absorption by SAP I minimized GGBS effect on the consistency.

Another fresh state property that has been affected by addition of SAP in mortars was air content, whose graph with the test results is shown in Figure 8. In general view, SAP increased the air content of fresh mixes.

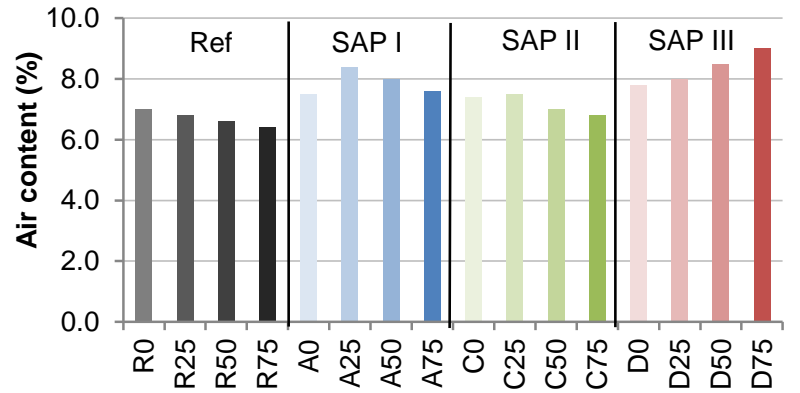

Figure 8. Air content of fresh state mortars.

In comparison with reference samples, mortars with SAPs had increment of $18 \%, 7 \%$ and $24 \%$ for overall average for mixtures with SAP I, II and III respectively. This group behaviour may be related to the flow results (Figure 7) in an inversely proportional way. The greater consistency the lower air content values by group analysis between mortars without and with different types of SAPs, independently of GGBS level. Reference samples had the highest flow values and the lowest air content results. This trend is followed by the order of SAP II, SAP I and SAP III (this last one with the highest average values of air content). Therefore, SAP water absorption may cause the mixture to be drier and contain more air.

Air content may also influence density in fresh state mortars, as shown in Figure 9. Overall mortars with SAPs had a reduction in about $2 \%$ on the density compared with reference samples.

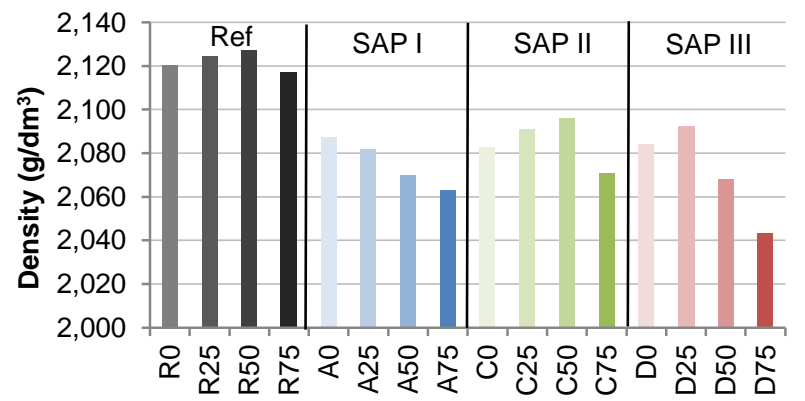

Figure 9. Density of fresh state mortars.

All samples with SAPs had their density decreased because the water absorption by SAP may have provoked a slight swelling in the mixture, once SAP can increase their volume in the presence of water in cement paste solution. In studies with SAP absorption capacity, Esteves (2011) has verified that SAP dry particles with $50 \mu \mathrm{m}$ to $500 \mu \mathrm{m}$ of diameter reached sizes of $100 \mu \mathrm{m}$ to $1400 \mu \mathrm{m}$ of diameter in the presence of synthetic cement-based pore fluid. The water is absorbed by SAP and hence getting drier mixtures, followed by a slight swelling in the mixture, leading to increase of its volume. This increment of volume to the same amount of materials compared with reference samples leads to 
reduced density of fresh state mortars with SAPs, whatever their water absorption capacity. It appears that GGBS addition does not affect the density of fresh state mortars.

Table 4 and Figure 10 show the results of initial and final setting times of the studied mortars. As expected, GGBS has increased the final setting time for all samples compared with mortars with lower/no GGBS contents.

Table 4. Tests results of setting times.

\begin{tabular}{ccc}
\hline Sample name & $\begin{array}{c}\text { Initial setting } \\
\text { time (h:min) }\end{array}$ & $\begin{array}{c}\text { Final setting } \\
\text { time (h:min) }\end{array}$ \\
\hline R0 & $02: 43$ & $03: 38$ \\
R25 & $03: 04$ & $04: 50$ \\
R50 & $03: 24$ & $05: 55$ \\
R75 & $03: 36$ & $09: 28$ \\
\hline A0 & $01: 54$ & $05: 02$ \\
A25 & $01: 49$ & $07: 02$ \\
A50 & $01: 35$ & $07: 33$ \\
A75 & $01: 26$ & $09: 06$ \\
\hline C0 & $02: 04$ & $03: 23$ \\
C25 & $02: 05$ & $04: 06$ \\
C50 & $02: 55$ & $06: 54$ \\
C75 & $03: 19$ & $07: 27$ \\
\hline D0 & $01: 37$ & $04: 04$ \\
D25 & $01: 54$ & $06: 07$ \\
D50 & $02: 31$ & $08: 51$ \\
D75 & $02: 38$ & $09: 49$ \\
\hline
\end{tabular}

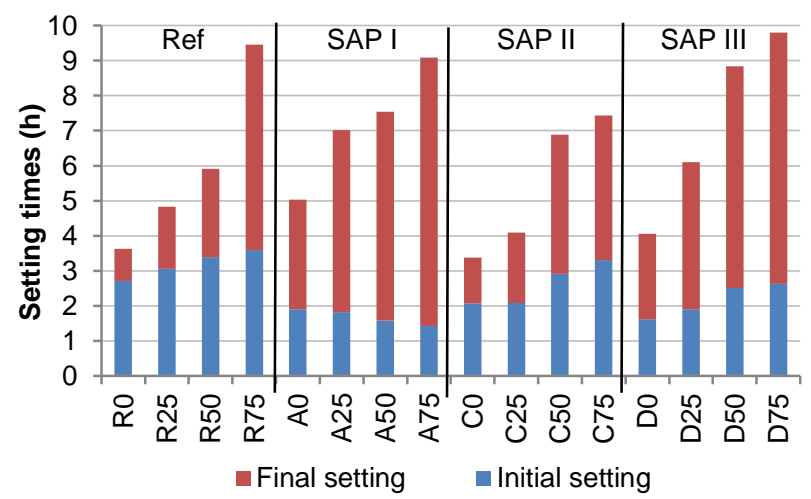

Figure 10. Setting times of mortars (in hours).

Initial setting times for mortars with SAPs seem to be lower than those for reference samples. The free water that has not been absorbed by SAP may be sufficient to initiate hydration process in a faster way in comparison with mortars without SAP. Moreover, mortars with SAP I seemed to have a different pattern compared with other samples, showing acceleration in initial setting time with higher GGBS contents. It can indicate that SAPs may have different water absorption kinetics, which can also be affected by addition of GGBS in the mixture, leading to different behaviour at the start of hydration process.

Regarding final setting time, mortars with higher levels of cement replacement by GGBS had their final setting retarded due to GGBS slower hydration process compared to CEM I. The higher is the GGBS content, the higher is the final setting time. Moreover, it was not possible to identify any pattern related to the addition of different type of SAP in the mixture, suggesting that SAP may not influence the final setting time significantly. It can indicate that free water that has not been absorbed by SAP is able to initialize the hydration process in the same way as a reference sample. After that, SAP might still store water for further reactions.

The results of final setting time were used to determine the initial measure for autogenous shrinkage testing, whose results are shown in Figure 11. Overall, SAPs clearly reduced autogenous shrinkage compared with reference mortars over 28 days of testing.

Considering reference samples without SAP, autogenous shrinkage was continuously increased over the time and it also was affected by different GGBS contents. The higher the level of cement replacement by GGBS, the greater is the autogenous shrinkage. At the end of 28 days, there was shrinkage about $350,480,560,640 \mu \mathrm{m} / \mathrm{m}$ for mortars with $0 \%, 25 \%, 50 \%$ and $75 \%$ of GGBS, respectively. This behavior was also verified by other authors that state the greater values of autogenous shrinkage with GGBS may be due to its higher degree of hydration, and therefore, a greater degree of self-desiccation (Lee et al. 2006; Bouasker et al. 2014; Jiang et al. 2014; Valcuende et al. 2015). According to the authors, the greater chemical shrinkage led to faster and greater self-desiccation, and results in larger autogenous shrinkage. Besides that, the use of GGBS makes pores structure of mortar finer, which leads to increase of autogenous shrinkage. The smaller capillaries the higher tensile stress provoked by the water menisci in the capillaries. This finer pore structure in the fresh state mortars studied may be inferred by the air content results test (Figure 8). Mixes with higher quantities of GGBS presented lower air content, and it may have led to more compacted mixtures resulting in finer pore structure of fresh mortars. Valcuende et al. (2015) also verified the higher GGBS content used the higher the total pore volume and hence the cementitious material is more prone to deformation. 

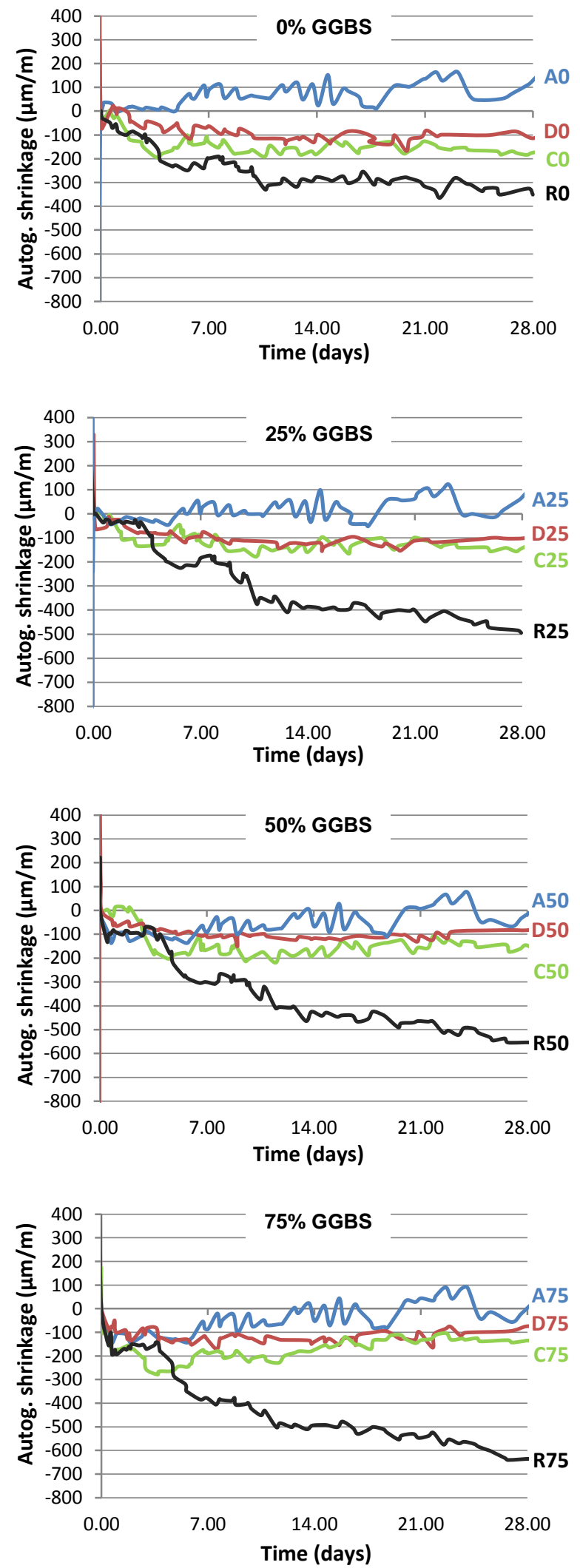

Figure 11. Autogenous shrinkage results - comparison by same levels of cement replacement by GGBS.

However, in the presence with SAPs, this behavior was sharply altered showing a significantly reduction in autogenous shrinkage for all levels of cement replacement by GGBS. Autogenous shrinkage was mitigated when using internal curing through SAPs in mortars with GGBS, and it was also verified by others authors who studied the effect of SAP on cement paste with GGBS (Snoeck et al. 2015). The principle of internal curing by means of SAP relates to the provision of water-filled cavities in hardened mortars, reducing autogenous shrinkage (Beushausen et al. 2014).

Regarding the studied samples, those with SAP II and III had similar performance, presenting shrinkage values between 100 and $200 \mu \mathrm{m} / \mathrm{m}$ for all mortars studied during the 28 days. These values represent reduction in order of $50 \%, 65 \%, 70 \%$ and $80 \%$ for mortars with $0 \%, 25 \%, 50 \%$ and $75 \%$ of GGBS, respectively, in comparison with reference mortars without SAP and same GGBS contents. It suggests that SAP has a significant effect on autogenous shrinkage reduction, especially for high contents of GGBS when this diminution is maximized.

Beside the considerable reduction in autogenous shrinkage, specimens with SAP I had a slight swelling. Samples with low GGBS content $(0 \%$ and $25 \%$ ) had predominant swelling since their first week and getting values around $100 \mu \mathrm{m} / \mathrm{m}$ of expansion. However, for samples with higher GGBS contents $(50 \%$ and $75 \%)$, shrinkage was noticed in the first weeks (not more than $100 \mu \mathrm{m} / \mathrm{m}$ of shrinkage) but, after that, the specimens had their size increased, getting shrinkage virtually nil at the end of 28 days. Snoeck et al. (2015) also noticed expansion in their samples with SAP and GGBS. According to the authors, swelling capacity of SAPs may be expected to be different between the mixtures since the ion concentration in pore fluid is different and the type of polymer present different performances.

\section{CONCLUSIONS}

From the results obtained in the experimental study, the following can be concluded:

- SAP and GGBS affects mortar workability, once they reduce its consistency due to SAP's high water absorption capacity and GGBS's smaller specific surface area compared with a reference mortar;

- The increase of air content and the reduction of density in fresh state mortars with SAP may be related to the water absorption by SAP and hence getting drier mixtures, followed by a slight swelling in the mixture;

- Mortars with SAP can significantly reduce autogenous shrinkage for any studied GGBS content in comparison with the reference mortar. Autogenous shrinkage of mortars 
with high quantity of GGBS can be reduced in other of $80 \%$ for SAP II or III, and up to $100 \%$ considering SAP I. The reduction of autogenous shrinkage by SAP may decrease the cracking susceptibility and hence increase the sustainability level of the material for more durable constructions.

\section{ACKNOWLEDGEMENTS}

The authors acknowledge CNPq (Conselho Nacional de Desenvolvimento Científico e Tecnológico Brazil) for the financial support, Hanson Cements for CEM I and GGBS supply, and BASF for SAPs supply.

\section{REFERENCES}

ASTM Standard, 2009. Standard test method for autogenous strain of cement paste and mortar. ASTM C-1698.

Beushausen, H., Gillmer, M. \& Alexander, M., 2014. The influence of superabsorbent polymers on strength and durability properties of blended cement mortars. Cement and Concrete Composites, 52:73-80.

Bouasker, M. et al., 2014. Early-age deformation and autogenous cracking risk of slag-limestone fillercement blended binders. Construction and Building Materials, 55:158-167.

BSI, 1998. Methods of test for mortar for masonry part 6: determination of bulk density of fresh mortar. BS EN 1015-6.

BSI, 1998. Methods of test for mortar for masonry part 7: determination of air content of fresh mortar. BS EN 1015-7.

BSI, 1999. Methods of test for mortar for masonry part 3: determination of consistence of fresh mortar (by flow table). BS EN 1015-3.

BSI, 2005. Methods of testing cement - part 3: determination of setting times and soundness. BS EN 196-3.

BSI, 2006. Ground granulated blast furnace slag for use in concrete, mortar and grout. Definitions, specifications and conformity criteria. BS EN 15167-1.

BSI, 2011. Cement - part 1: composition, specifications and conformity criteria for common cements. BS EN 197-1.

BSI, 2013. Aggregates for mortar. BS EN 13139.

Esteves, L.P., 2011. Superabsorbent polymers: On their interaction with water and pore fluid. Cement and Concrete Composites, 33(7):717-724.

Hasholt, M.T. et al., 2012. Can superabsorent polymers mitigate autogenous shrinkage of internally cured concrete without compromising the strength? Construction and Building Materials, 31:226-230.
Jensen, O.M. \& Hansen, P.F., 2001. Water-entrained cement-based materials. Cement and Concrete Research, 31(4):647-654.

Jensen, O.M. \& Hansen, P.F., 2002. Water-entrained cement-based materials: II. Experimental observations. Cement and Concrete Research, 32:973-978.

Jiang, C. et al., 2014. Autogenous shrinkage of high performance concrete containing mineral admixtures under different curing temperatures. Construction and Building Materials, 61:260-269.

Klemm, A.J., Baker, P. \& Sikora, K., 2012. The effect of super absorbent polymers on the performance of immature cementitious mortars. In Brittle Matrix Composites 10. Warsaw: Elsevier, pp. 21-31.

Klemm, A.J. \& Sikora, K.S., 2013. The effect of Superabsorbent Polymers (SAP) on microstructure and mechanical properties of fly ash cementitious mortars. Construction and Building Materials, 49:134-143.

Lee, K.M. et al., 2006. Autogenous shrinkage of concrete containing granulated blast-furnace slag. Cement and Concrete Research, 36(7):1279-1285.

Mechtcherine, V. et al., 2013. Effect of internal curing by using superabsorbent polymers (SAP) on autogenous shrinkage and other properties of a high-performance fine-grained concrete: results of a RILEM round-robin test. Materials and Structures, 47(3):541-562.

Mechtcherine, V. \& Reinhardt, H.-W., 2012. Application of Superabsorbent Polymers (SAP) in Concrete Construction, Springer.

Oner, A. \& Akyuz, S., 2007. An experimental study on optimum usage of GGBS for the compressive strength of concrete. Cement and Concrete Composites, 29(6):505-514.

Siddique, R. \& Bennacer, R., 2012. Use of iron and steel industry by-product (GGBS) in cement paste and mortar. Resources, Conservation and Recycling, 69:29-34.

Snoeck, D., Jensen, O.M. \& De Belie, N., 2015. The influence of superabsorbent polymers on the autogenous shrinkage properties of cement pastes with supplementary cementitious materials. Cement and Concrete Research, 74:59-67. Valcuende, M. et al., 2015. Shrinkage of selfcompacting concrete made with blast furnace slag as fine aggregate. Construction and Building Materials, 76:1-9. 